\title{
Educação sexual entre a escola e a família: afinidades difíceis de afinar
}

\author{
Sexual education between school and family: affinities difficult to adjust
}

José Manuel Resende, David Beirante e Luís Gouveia'

\section{Resumo}

Escola pública e famílias são instituições onde, ora se articulam ora se litigam, valores, saberes e responsabilidades sobre a educação sexual dos jovens escolares. Apesar das políticas educativas apontarem resolutamente para uma dinâmica de articulação entre estas instituições, surgem frequentemente tensões, dilemas e controvérsias, que indiciam uma difícil articulação na concretização dos projetos de educação sexual na escola pública portuguesa. Neste sentido, o presente artigo tem por objetivo analisar e interpretar os argumentos esgrimidos por pais e professores sobre a quem compete coordenar, guiar e apoiar estas ações educativas. Com base neste objetivo, foi mobilizado um protocolo metodológico que envolve um conjunto diversificado de técnicas de recolha de dados: entrevistas; questionários; observação etnográfica e pesquisa documental. Em traços gerais, esta pesquisa empírica permite concluir que apesar das referidas tensões entre a escola e a família, uma lógica associada à proteção e ao bem-estar físico e emocional juvenil, presente nos programas de educação sexual escolar, é fundamental para encontrar sentidos de coordenação entre as duas instituições.

\section{Palavras chave}

Educação sexual, responsabilidade, escola, família, íntimo, público.

\section{Abstract}

The public school and the families are institutions where knowledge and responsibilities on sexual education are articulated or sometimes enter in conflict. Although educational policies point firmly to a dynamic of articulation between the two institutions, some tensions suggest a difficult articulation in sexual education in Portuguese public school. In fact, this article aims to analyse and interpret the arguments of parents and teachers about who is responsible for coordinating, guiding and supporting these educational actions. Based on this objective, a methodological protocol was mobilized by a set of data collection techniques: interviews; questionnaires; ethnographic observation and documentary research. In general terms, this empirical research allows us to conclude that, despite the aforementioned tensions between school and family, a logic associated with youth physical and emotional well-being and protection, present in school sex education programs, is fundamental to find coordination between the two institutions.

\section{Keywords}

Sex education, school, responsibility, family, intimate, public. 


\section{Introdução}

\section{Educação sexual na escola e na família entre (des)afinações e (des)compassos}

O reconhecimento pela Assembleia da República Portuguesa de que a educação sexual dos jovens escolares é uma das dimensões fundamentais da educação para a saúde das populações, levou à aprovação, em 2009, de um conjunto de princípios e regras quanto à organização funcional da educação sexual em meio escolar (Lei n. ${ }^{\circ}$ 60/2009, de 6 de agosto) ${ }^{2}$. Este diploma estabelece a obrigatoriedade da implementação de programas regulares de educação sexual em todos os níveis de ensino, com uma duração mínima de 6 horas no $1 .^{\circ}$ e $2 .^{\circ}$ Ciclos do Ensino Básico, e com uma duração mínima de 12 horas no $3 .^{\circ}$ Ciclo do Ensino Básico e do Ensino Secundário.

As diretrizes ventiladas pela referida Lei, enumeram ainda justificações que vão ao encontro da necessidade de implementação de programas regulares de educação sexual nas escolas públicas portuguesas. Estas justificações permanecem ancoradas aos seus conteúdos fundamentais, assim como aos princípios que os enformam -as expressões da sexualidade, que incluem a promoção da saúde sexual e reprodutiva, a identidade sexual, a corporeidade e o corpo, os afetos- ao mesmo tempo que lançam expectativas sobre como estes princípios são (ou não) apropriados de forma reajustada por parte dos alunos.

Na última época, a sexualidade juvenil configura-se como uma questão cultural, social e politicamente sensível, ganhando o estatuto de problema público que justifica a implementação da educação sexual nas escolas, objetivando prevenir a (re)produção de condutas sexuais que de alguma forma possam recortar perigos para a saúde física e/ou emocional dos adolescentes e jovens. A par de problema público, a sexualidade juvenil é ainda um problema político, pois se por um lado, há um certo acordo social de que estes problemas merecem uma intervenção educativa organizada (Gore et al., 2011), por outro, despontam divergências quanto aos processos que a mesma envolve, a amplitude e profundidade dos seus efeitos, os espaços sociais onde esta deve ocorrer e principalmente a quem cabe fazê-lo (Shepherd et al., 2010).

Sobre este último tópico, importa referir que a escola e as famílias são instituições onde, ora se articulam ora se litigam, conhecimentos e responsabilidades sobre os exercícios qualificantes tidos como mais ou menos relevantes na ação planificada de educar a sexualidade juvenil. Estes exercícios qualificantes, por serem delicados face a esta temática, envolvem técnicas e procedimentos pedagógicos questionáveis perante os desafios emergentes acerca do modo como os educadores desenvolvem a ação pedagógica sobre a sexualidade, em confronto com outros desafios trazidos pela trama que combina a figura estatuária do aluno com a figura do adolescente e do jovem³ que se encontra na audiência (Resende et al., 2016 ).

O objetivo deste artigo é precisamente dar conta de como se coordenam (se é que se coordenam), pais e educadores com vista a educar adolescentes e jovens sobre a sua tutela para a sexualidade. Fazemo-lo considerando os argumentos esgrimidos pelos conflitos e pelos consentimentos estabelecidos (mesmo que tácitos) manifestados pelos atores que participam na educação sexual escolar em torno de uma questão estruturante: que entidade tem autoridade, responsabilidade e arcabouço para levar a cabo a educação sexual dos jovens escolares: escola, família ou ambas?

2 Constituem finalidades da educação sexual: a valorização da sexualidade e afectividade entre as pessoas no desenvolvimento individual, respeitando o pluralismo das concepções existentes na sociedade portuguesa; o desenvolvimento de competências nos jovens que permitam escolhas informadas e seguras no campo da sexualidade; a melhoria dos relacionamentos afectivo-sexuais dos jovens; a redução de consequências negativas dos comportamentos sexuais de risco; a capacidade de proteção face a todas as formas de exploração e de abuso sexuais; o respeito pela diferença entre as pessoas e pelas diferentes orientações sexuais; a valorização de uma sexualidade responsável e informada; a promoção da igualdade entre os sexos; a compreensão científica do funcionamento dos mecanismos biológicos reprodutivos (Decreto-Lei 60/2009).

3 Sublinham-se estas duas categorias, justamente porque as pesquisas têm como palco os agrupamentos de escolas do terceiro ciclo do ensino básico e do ensino secundário, abrangendo alunos de uma faixa etária entre os 12 e os 18 anos. 
Se é certo que as políticas públicas apontam resolutamente para a criação de dinâmicas de partilha e articulação entre a escola e a família nas ações de educar para a sexualidade (Reis e Vilar, 2004) -aspiração intensamente vinculada pelo legislador de que «os encarregados de educação, os estudantes e as respetivas estruturas representativas devem ter um papel ativo na prossecução e concretização das finalidades da

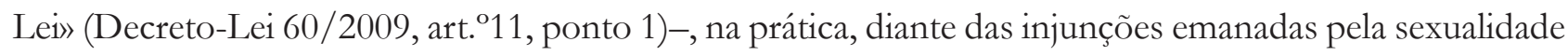
juvenil, existem (des)articulações a ter em conta. Ou seja, se é inegável a existência de uma certa interdependência entre as duas instituições supracitadas, com tendência para o que se constrói numa afete invariavelmente a outra, existem tensões e disputas de natureza diversa que envolvem a relação entre saberes, afetos e valores produzidos por cada uma delas. Estas tensões tornam-se particularmente visíveis quando as críticas, pontualmente presentes nos discursos atuantes dos atores, mostram que apesar da educação sexual ser hoje uma realidade que não oferece uma oposição explícita por parte das famílias, não deixa de ser pontuada por inquietações, queixas ou controvérsias, trazidas em forma de arbitragens complexas feitas por pais e professores (Resende et al., 2016).

No presente artigo, descrevemos e analisamos as posições críticas dos atores face à problemática enunciada. Para tal, recompomos cenas empíricas quotidianas, ao mesmo tempo que sistematizamos argumentos considerados pertinentes, a fim de dar conta de como os atores se envolvem na educação sexual juvenil. Trata-se, enfim, de «seguir os atores» (Thévenot, 2014) nas interações e práticas da vida quotidiana, processo que implica levar a sério os argumentos que os mesmos mobilizam como justificação das suas atividades críticas, assim como das formas plurais como agem com os outros: uma máxima do estilo pragmático francês desenvolvido por Luc Boltanski e Laurent Thévenot nos anos 80 e que constitui o principal marco teórico desta pesquisa.

\section{Metodologia}

\section{Seguir os atores: os fundamentos de uma abordagem pragmática}

A orientação metodológica aqui presente atende o propósito de organizar, de forma adequada, os potenciais ensinamentos empíricos captados no terreno de pesquisa. Trata-se, portanto, de desenvolver, através de métodos essencialmente etnográficos, abordagens e concepções que permitam reconhecer e apreender, de acordo com os significados que os sujeitos atribuem às suas atividades e ao contexto onde estas se desenrolam, a pluralidade de formas de fazer o comum entre atores nos seus quotidianos (Thévenot, 2006, Resende, 2010).

O material empírico a partir do qual se organizou este artigo foi obtido através de uma abordagem metodológica qualitativa, recorrendo a um conjunto diversificado de técnicas de recolha de dados e de fontes documentais: opção que se justifica pela complexidade do objeto estudado, e pelo referido interesse nas atividades do dia-a-dia dos sujeitos no que diz respeito a educar para a sexualidade, tanto na sua execução, como na construção de um contexto de interação, localmente orientado, onde as atividades são realizadas.

A informação foi obtida através de entrevistas semiestruturadas, questionários, observação etnográfica e pesquisa documental. Com efeito, foram efetuadas entrevistas a 25 professores $^{4}$ do $3 .^{\circ}$ ciclo do ensino básico e secundário que participam ou participaram em projetos de educação sexual escolar. A pesquisa desenvolveu-se em três agrupamentos de escolas ${ }^{5}$ do território nacional, com uma população estudantil

410 na escola A, 7 na escola B e 8 na escola C.

5 Um agrupamento de escolas é uma unidade organizacional educativa dotada de órgãos próprios de administração e gestão, constituída por estabelecimentos de 
que evidencia uma composição cultural heterogénea e contrastante. Um dos agrupamentos de escolas situa-se no centro da cidade de Lisboa (escola A), outro está na periferia urbana da mesma cidade (escola B), e o terceiro localiza-se no interior-centro do país (escola C). Foram ainda realizadas 21 entrevistas $^{6}$ a pais e/ou encarregados de educação de alunos pertencentes a escolas dos mencionados agrupamentos. Aos dados obtidos através de entrevista juntam-se outros provenientes de 137 questionários (117 a professores $^{7}$ e 20 a pais e/ou encarregados de educação) ${ }^{8}$. O período de recolha de dados decorreu entre dezembro de 2013 e março de 2017.

O guião semiestruturado das entrevistas foi concebido após uma primeira incursão exploratória no terreno de pesquisa com duração de três meses, entre dezembro e fevereiro de 2013. Os dados recolhidos desta incursão permitiram introduzir questões e lançar algumas hipóteses sobre o objeto em análise. Esta primeira incursão e outras que se lhe seguiram (em períodos de permanência mais alargados), foram efetuadas com base nos princípios da observação participante, como uma estratégia de campo que combina a análise documental (documentos legislativos e normativos, Planos de Educação para a Saúde e Projetos de Educação Sexual das Turmas, ambos produzidos nas escolas); a entrevista etnográfica a sujeitos e informantes; a participação e observação diretas, e a introspeção.

A realização de pesquisas etnográficas no terreno, privilegiaram o acompanhamento de sessões dedicadas à educação sexual (32 no total) e outras iniciativas feitas na escola no mesmo âmbito, assim como reuniões dos Conselhos de Turma (15 no total) ou Assembleias de Pais e Encarregados de Educação (7 no total) onde os projetos de educação sexual foram debatidos.

$\mathrm{Na}$ pesquisa etnográfica, caracterizada por uma permanência prolongada no terreno ( 6 a 8 meses), o posicionamento do investigador presente no aqui e agora das situações do dia-a-dia, são características de um processo de «vai e vem» entre o terreno e a análise dos dados aí recolhidos. Desta análise foi produzido um conjunto renovado de questões e hipóteses, que levaram a novas incursões no terreno (desta feita menos prolongadas). Seguimos, portanto, uma lógica e um processo de pesquisa aberto e flexível que exigiu contínua redefinição do que é problemático perante os discursos dos atores e os factos observados nos contextos concretos onde a ação decorre.

A população em estudo é constituída por professores e pais/encarregados de educação envolvidos na educação sexual escolar. A dimensão e composição da amostra (não representativa do ponto de vista estatístico) foi determinada a partir de uma estratégia gradual de amostragem conhecida como «bola de neve». Este método consiste em pedir a cada entrevistado, de cada uma das três escolas, que indique o nome de outros possíveis entrevistados, constituindo gradualmente a referida amostra. A amostragem prossegue, de acordo com a relevância dos casos, até atingir a chamada «saturação teórica», ou pelo menos, quando a informação obtida permite lançar luz sobre as principais interrogações e inquietações que o tema em análise suscita.

\footnotetext{
educação que podem ir do pré-escolar ao ensino secundário, incluindo todos os ciclos intermédios $\left(1 .^{\circ}, 2 .^{\circ}\right.$ e $\left.3 .^{\circ}\right)$.

65 entrevistas na escola A, 9 na escola B e 7 na escola C.

741 na escola A, 37 na escola B e 39 na escola C.

89 na escola A, 5 na escola B e 6 na escola C.
} 


\section{Educação sexual escolar: responsabilidade, alteridade e conhecimento}

No articulado da lei nº0/2009, os princípios individuais da autonomia e da responsabilidade (capacitando os jovens para escolhas informadas e seguras no campo da sexualidade), da alteridade (respeito, igualdade, reconhecimento do outro) e do conhecimento (do funcionamento dos mecanismos biológicos reprodutivos), estão na base da sua recente proeminência social (estando os seus conteúdos sempre sujeitos a revisão pois são permeáveis aos tópicos sociais emergentes relacionados com a sexualidade) .

As categorias aludidas da responsabilidade, alteridade e conhecimento servem de dispositivos políticos e morais para a mobilização das ações coletivas sobre a sexualidade juvenil, a celebrar em contextos escolares contrastantes, e adquirindo uma importância fulcral na coordenação dos atores e nas dinâmicas das ações perpetradas neste âmbito.

Á categoria da responsabilidade corresponde uma concepção multifacetada que constitui, de certa forma, uma primeira zona de polémica. Com efeito, atribui-se a responsabilidade à autoridade pública pela produção legislativa que traça as linhas mestras para a implementação de programas regulares de educação sexual em meio escolar. Às escolas cabe a responsabilidade da criação de programas, redes e grupos de trabalho, com o fim de coordenar, guiar e apoiar a ação dos diferentes intervenientes na educação sexual. Aos educadores - professores ou outras figuras convidadas pela escola- pede-se que assumam a responsabilidade de garantir uma (boa) educação sexual, concretizando as finalidades estabelecidas pela Lei. Aos pais e/ou encarregados de educação, solicita-se a responsabilidade de um exercício de colaboração com as escolas, mas sem descurar a função de escrutínio em relação a todas as atividades curriculares e não curriculares desenvolvidas no âmbito da educação sexual aí ministrada. Finalmente, aos alunos, exige-se que se autonomizem e se responsabilizem pelos seus atos sexuais, por forma a não incumbirem em comportamentos de risco que possam produzir efeitos desajustados e, por conseguinte, indesejáveis, tanto do ponto de vista pessoal (suspensão ou desistência de uma carreira escolar, por exemplo), como perante aqueles que lhes são próximos (sofrimento das famílias, custos associados a cuidados ou tratamentos) ou ao tecido social (aumento do número de grávidas adolescentes, proliferação de infeções sexualmente transmissíveis). Há, portanto, aqui uma cadeia intrincada de responsabilidades a ser considerada (Lazarus et al., 2010; Sheperd, 2010).

Uma segunda zona de polémica versa precisamente sobre aquilo que os diferentes atores envolvidos na educação sexual escolar assumem como «atos responsáveis» em «formas plurais de fazer a educação sexual na escola», ou seja, como se configuram, conjugam e harmonizam exercícios de desempenho dos vários atores em torno de um propósito comum.

Como aludimos anteriormente, ao nível do aluno, a responsabilidade é pensada a partir do conceito de autonomia. Assim, o adolescente ou jovem deve ser devidamente preparado para estar apto a fazer escolhas informadas e seguras no campo da sexualidade, ou seja, deve capacitar-se para saber escolher, tomar decisões, saber gerir-se, quer no sentido da emancipação individual, quer no sentido da sua responsabilidade cívica (Dionísio, 2015).

Fazer a escolha certa significa não ter de suportar o peso de várias frustrações e insatisfações ao longo da sua vida sexual. Ao invés, fazer a escolha errada, obriga a carregar um fardo insustentável equivalente ao «trágico», nem sempre passível de reversibilidade ou de remediação. A maioria dos cenários para os quais se incentiva o jovem a fazer escolhas, aduzidos em sessões de educação sexual nas escolas, são altamente polarizados e dicotomizados, uma escolha de vida ou de morte. Por exemplo: usar preservativo 
ou contrair uma doença grave; usar contracepção ou enfrentar uma paternalidade/maternalidade não desejada.

Estes cenários não são imunes à dura crítica por parte de quem denuncia serem exacerbadamente «dramáticos, constrangedores, opressores e sensacionalistas, exercendo sobre o aluno uma forma de repressão, castrando a sua liberdade [...]» (professor de história, 49 anos, escola na zona periférica de Lisboa).

O sistema de ensino da atualidade afirma-se contra o espírito da repressão e da sanção que vigorava no passado, em favor do respeito pela individualidade e pela vida independente dos adolescentes e dos jovens escolares. A palavra-chave deixou de ser disciplina, e foi progressivamente substituída por outras, tais como o reconhecimento da singularidade pessoal e o desenvolvimento da autonomia responsável. A «ação que convém» (Thévenot, 1990) à educação já não é a opressão, mas sim o respeito e o favorecimento da individualidade da pessoa do aluno num ambiente escolar de afeção, cuidado e compreensão.

Apesar da maioria dos pais ( $80 \%$ dos inquiridos) apoiarem a ideia da autonomização dos filhos, estimulados para a escolha individual responsável, esta ideia não reúne um acordo generalizado. Com efeito, nos pontos de vista atuantes de alguns pais entrevistados, a relação entre autonomização e permissividade é equacionado em termos do desenvolvimento de seres educados usando regras, sem a figura de autoridade, sem que se apercebam qual a sua posição, sem os constrangimentos considerados por estes pais como indispensáveis para construir e estruturar a personalidade dos jovens.

Nas suas explanações práticas encontramos ainda outro receio: que um certo alívio dos controlos por parte das figuras adultas, responsáveis pela educação sexual nas escolas, venha a resultar num aligeiramento das regras comportamentais dos seres sob a sua tutela, que se tornam demasiado flexíveis, menos normalizadoras, mais frouxas, mais arbitrárias. Na sua opinião, os princípios morais defendidos na família correm o risco de serem subvertidos pelo encorajamento do jovem autónomo, que procura viver uma sexualidade desafogada e livre de qualquer condicionamento social (Resende et al., 2016).

Assim, a educação sexual «permissiva» é tomada como uma força que invade de forma hostil o mundo privado da família, e progressivamente vai desfazendo os laços afetivos familiares e tecendo outros vínculos que afastam o adolescente da família para o tornar num ser desligado, descomprometido, solto, irresponsável. Cada atentado a este espaço familiar provoca sequelas e sofrimentos tanto ao próprio individuo, como a familiares e amigos, cuja reversibilidade depende do tipo de danos provocados (Breviglieri, 2005).

Sobre este aspeto, resta-nos salientar que a fabricação de uma autonomia responsável resulta de um exercício de composição entre as escolhas que os jovens assumem como pessoais, valorizando uma sexualidade responsável e informada, gerindo de forma autónoma a sua vida sexual (entre oportunidades, constrangimentos, inquietações) e pelas ações publicamente reconhecidas como válidas porquanto cimentadas na construção de uma ordem comum (Dionísio, 2015), donde se destacam a prevenção de riscos de índole sexual, a redução dos problemas sociais que uma atitude irresponsável acarreta não só ao indivíduo como também aos outros que contam (Taylor, 2005), quer sejam próximos ou desconhecidos, mas reconhecidos como pertencentes a uma humanidade comum (Resende, 2010).

O sociólogo Norbert Elias elucida-nos precisamente sobre o processo que tende a equilibrar as interações «Nós-Eu», comandadas na primeira pessoa do singular (Elias, 1993), tendo em conta que à medida 
que os processos de singularização avançam, eles não se circunscrevem ao individuo, mas ao programa institucional da escola (Dubet, 2002; Dionísio, 2015) e ao trabalho dos profissionais convocados para o efeito. O indivíduo autónomo, cuidador de si, livre das amarras do controlo de uma tirania do próximo exercida pelas famílias ou pelos amigos (Pasquier, 2005), passa a valorizar a intimidade, o amor e a sexualidade como fontes de gratificação e realização pessoal (Aboim, 2013).

Caso contrário, acentua a sua imaturidade no momento da escolha (deixando que os outros a condicionem), e trava o itinerário autónomo que lhe permite atravessar a fronteira que separa «uma espacialidade de vínculos afetivos do mundo próximo e familiar de uma outra de implicação moral do domínio público» (Breviglieri, 2007:18).

O trabalho dos professores sobre a pessoa do aluno, em prol da capacitação do mesmo para incumbir em escolhas autónomas, responsáveis e seguras, exige um constante exercício de ajustamento recíproco entre as figuras adultas e os jovens sob a sua tutela, em detrimento daquilo que muitos entendem como um movimento de fundo de uma geração adulta que, ante a vaga de anomia de uma geração mais nova, aproveita para exercer uma influencia repressiva e castradora da sua autonomia.

O referido trabalho é composto em regimes de envolvimento, racionalidades e formas de legitimação múltiplas (Thévenot, 2006), e não se encontra isento da vigilância acurada ou da constante suspeita por parte das famílias, incorrendo no risco de que uma falsa percepção recaia sobre o mesmo, gerando equívocos ou mal-entendidos (Ichheiser 1949, Breviglieri, 2009). Com efeito, alguns pais possuem dúvidas sobre aspetos particulares do trabalho dos professores, pois receiam que a liberdade de consciência dos seus filhos seja violada ou a estrutura moral recebida da família seja destruída.

A educação sexual, vista segundo uma lógica de proximidade, deve então encontrar as modalidades (nas mais variadas combinações criativas) que os educadores consideram melhor ajustadas à mobilização e envolvimento dos alunos na construção de um projeto de vida autónomo. Este propósito exige uma organização escolar apetrechada com os dispositivos políticos ou relacionais adequados para cumprir os propósitos da Lei (Breviglieri, 2005, Pattaroni, 2007) que lhes permita ajustar os processos educativos às especificidades de cada caso (Dionísio, 2015).

\section{Seguir uma pauta ou improvisar?}

A educação sexual escolar é, desde a sua criação, povoada por uma pluralidade de controvérsias, não só quanto às modalidades e dispositivos que melhor se ajustam aos seus propósitos essenciais, como também aos projetos ideológicos e às questões de ordem moral que visam modelá-la em termos de valores, modos de ser e de fazer e responsabilidades. Assim, a uma pluralidade de justificações, específicas ou gerais, correspondem significações múltiplas que, por sua vez, exploram caminhos diferentes e exprimem propósitos (aparentemente) irreconciliáveis a propósito da educação sexual escolar.

Sérgio 9 é pai e encarregado de educação de um jovem de 16 anos, aluno de uma escola secundária situada no centro de Lisboa. Segundo o mesmo,

"[...] a seguir à família [a escola] é a instituição à qual confiamos a educação dos nossos filhos. $\mathrm{Na}$ minha opinião, a escola tem a responsabilidade de abordar matérias relativas à prevenção de comportamentos de risco, mas também da transmissão de valores, desde que respeitem e integrem os valores

9 Dando cumprimento à garantia de anonimato, os nomes dos entrevistados são fictícios. 
recebidos pela família [...] Os pais devem não só colaborar nos projetos, como também permanecer atentos à educação sexual que os seus filhos recebem na escola». (Excerto de entrevista a encarregado de educação, 32 anos, realizada a 19 de outubro de 2016, escola A).

Segundo este pai, a responsabilidade de educar os jovens na sexualidade deve ser partilhada entre a escola e a família. No entanto, este modelo de partilha deve, segundo o mesmo, garantir uma fidelização aos valores transmitidos pela família que tomam precedência na educação de base dos adolescentes. Como instituição complementar à educação parental ou familiar, a escola, «a seguir à família», deve organizar-se num duplo intento: a prevenção de comportamentos de risco e a transmissão de valores. Escola e família devem então fomentar um protocolo de colaboração em prol de uma ordenação comum do mundo escolar onde agora se desenrola a educação sexual formalizada. Pais e/ou encarregados de educação devem apoiar e participar nos projetos, sem descurar a atenção vigilante da sua aplicação.

A difusão da ideia de uma responsabilidade partilhada entre a escola e a família, afirma-se, por parte de alguns pais e professores, como um exercício fundamental perante a função de educar a sexualidade juvenil. Facto reforçado por uma professora de filosofia entrevistada, coordenadora do Plano de Ação para a Saúde de um agrupamento de escolas no interior-centro do país:

\begin{abstract}
"[...] [a respeito da educação sexual] provavelmente o mais sensato é apontar para a colaboração entre a escola e as familias. O professor tem a vantagem do treinamento especifico para educar os alunos. Os pais têm a vantagem da proximidade familiar, do conbecimento mais próximo e da sua influência exercida através do testemunho diário. O professor estará eventualmente mais preocupado em aproximar a educação para a sexualidade aos valores sociais do quotidiano, como por exemplo, a igualdade de género ou o combate à descriminação com base na orientação sexual, da violência sexual [...] na grande maioria dos casos, penso que tanto a escola como as familias, cada uma com o seu papel, podem articular-se para dar aos jovens uma visão positiva da vida emocional e sexual, e, claro, fazế-los seres mais autónomos e responsáveis [...]》. (Excerto de entrevista a professora de Filosofia, 54 anos, realizada a 10 de novembro de 2015, Escola C).
\end{abstract}

Neste pequeno excerto de entrevista, podemos constatar que o discurso proferido acerca da educação sexual escolar segue uma lógica idêntica àquela que enforma o discurso patente no excerto de entrevista anterior. Num e noutro evidencia-se uma partilha ajustada entre a escola e a família sobre a educação sexual juvenil. Segundo esta professora, a responsabilidade compósita é feita a partir de uma diferenciação específica de exercícios de atos - diferentes na sua constituição e diversos na preponderância que atingem-, consoante a figura que o protagonista ocupa, pai/mãe ou professor, mas cuja mobilização e articulação assumem sentidos legítimos perante os adolescentes e os jovens visados.

A professora salienta ainda a importância da preparação dos seres juvenis para assumirem escolhas autónomas e responsáveis. Neste sentido, as competências visadas para «escolhas informadas e seguras» (Decreto-Lei 60/2009), «confecciona-se ainda pela preparação das competências para o cuidado e o (re) conhecimento de sì (Dionísio, 2015). A este propósito, emergem nas escolas novas formas de programação com o intuito de capacitar os jovens escolares para o exercício da autonomia responsável. Os projetos de educação sexual são um bom exemplo disso.

Este empreendimento feito pelas escolas, parte de uma ideia bastante difundida no espaço público de que a educação sexual escolar vem preencher uma insuficiência atribuída às famílias: a de estarem pouco capacitadas para lidar com as dúvidas e problemas levantadas pelos adolescentes numa temática tão sensí- 
vel como a da sexualidade. Não por alguma insuficiência de vínculos afetivos nas famílias, mas justamente por uma proximidade, digamos, demasiado próxima.

Não obstante, o envolvimento dos pais na educação dos filhos afigura-se indispensável, não só na perspetiva de constituírem um «porto seguro» disponível para acolher os adolescentes que ali regressam quando se sentem hostilizados pelas contingências do domínio público onde desejam afirmar-se (Breviglieri, 2007), mas também na capacidade de vigilância dos comportamentos dos filhos no campo da sexualidade, e das (re)apropriações que estes fazem das informações obtidas de fontes diversas: escola, pares, internet, etc.

De um modo geral, a maioria dos entrevistados, quer sejam professores, quer sejam pais ou encarregados de educação, revelam uma visão favorável à colaboração das famílias na educação sexual escolar com base em três gramáticas. Uma relacionada com a competência, partindo do princípio de que a missão socializadora da escola da «modernidade liberal alargada» (Wagner, 1996) não pode restringir-se à componente da instrução, devendo, ao invés, abordar assuntos referentes a valores e costumes, alicerçados tanto em «direitos universais» como na necessidade de integrar diferenças trazidas por outras culturas. A segunda gramática assenta nos princípios da autoridade, dado que a intervenção das autoridades públicas em matéria de educação sexual escolar tem vindo a materializar-se, para além da produção legislativa, na criação de programas, na formação de professores, de redes de apoio e grupos de trabalho, com o fim de coordenar, guiar e apoiar a ação educativa. Por fim, surge a gramática da responsabilidade (Pattaroni, 2007), dado que a educação para a sexualidade deve garantir que as ações exercidas pelos educandos cumpram o desiderato da criação de uma sexualidade saudável e feliz, impedindo ao mesmo tempo a continuação de condutas sexuais que recortem perigos para saúde física e/ou emocional dos jovens, e que possam resultar em certos efeitos tidos como «indesejáveis» no tecido social (infeções sexualmente transmissíveis, gravidez juvenil, discriminação em função do género ou da orientação sexual, violência sexual, etc.).

Apesar da maioria dos pais e/ou encarregados de educação se manifestarem a favor de uma educação sexual ministrada na escola, ainda que sobre o seu consentimento e vigilância, outros possuem uma visão adversa à aplicação de programas regulares de educação sexual em meio escolar. Esta visão é fundamentada pelo receio de que a mesma ocorra nas escolas de forma mais ou menos arbitrária, tanto quanto às formas como quanto aos conteúdos, carecendo de uma base racional e estrutural de identificação social para a sua aplicação pragmática. Para mais, o risco de subverter os valores transmitidos pela família é, segundo os mesmos, uma realidade que não deve ser ignorada, sendo que nestes casos, em vez de educar, a escola apenas estimula a curiosidade dos alunos, deixando aos impulsos e às pulsões rédea livre e daí ter como efeito o aumento, em vez da diminuição, da atividade sexual precoce e promíscua.

António é encarregado de educação do Martim de 13 anos que frequenta o 8. ano de escolaridade numa escola situada nos arredores de Lisboa. Mostra-se claramente apreensivo quanto à educação sexual em meio escolar:

«Não acredito, e fico preocupado, com o facto da escola tentar se substituir às famílias na educação sexual. A educação sexual deve ser feita em casa. São os pais e não os professores que têm a responsabilidade e que devem ter a iniciativa de educar os filhos para estas questões. Os professores e as professoras também são pais e mães e educam os seus filhos como bem entendem, segundo os valores que thes querem transmitir [...] muitos dos professores nem possuem nenhuma formação específica para a educação sexual, então fazem-no segundo o seu próprio sistema de valores que pode ser diferente da- 
quele que transmito aos meus filhos [...]》. (Excerto de entrevista a encarregado de educação, 45 anos, realizada a 13 de janeiro de 2016, Escola B).

Catarina, encarregada de educação de duas filhas, Filipa e Joana, com respetivamente 14 e 17 anos e que frequentam o mesmo agrupamento de escolas, quando questionada acerca da educação sexual escolar corrobora, em parte, a opinião do António:

«Não sou totalmente contra, mas também não fico completamente descansada em relação a isso. Não sei se os professores que dão a educação sexual na escola têm a formação suficiente para o que se propõem faz̧er. É uma responsabilidade muito grande e qualquer passo em falso pode induzir os jovens em erro e aumentar a sua curiosidade levando a que queiram experimentar a ter relações sexuais em idades muito precoces. Será que eles ouvem os professores mais do que os pais?». (Excerto de entrevista a encarregada de educação, 41 anos, realizada a 19 de maio de 2016, Escola B).

As dúvidas e incertezas patentes nestas entrevistas possuem um corpo comum: ambas apontam para a falta de formação dos professores e evidenciam o receio de que os valores familiares sejam subvertidos e os adolescentes se lancem num experimentalismo sexual desenfreado e inconsciente.

Todavia, outros motivos enformam outras críticas e objeções com graus de intensidade diferentes, mas que têm como denominador comum a asserção de que a interferência da escola pública, ou do Estado em sentido lato, em matérias de educação sexual deve ser reduzida, limitando-se ao ensino do funcionamento (biológico) do corpo humano. Já a educação sexual dos filhos, essa que ultrapassa as questões da biologia, é um direito (e um dever) exclusivamente parental ou familiar. Para estes, a escola deve ser fundamentalmente um espaço de instrução e por essa razão deve também abster-se de tratar matérias que impliquem a transmissão de valores e costumes que de alguma forma possam revolver aqueles que são transmitidos pela família. Cada macaco no seu galho, por assim dizer.

\section{Ensaiar composições criativas: fazer, desfazer e refazer novas musicalidades}

A sexualidade é hoje tida como um elemento crucial da realização da pessoa, da felicidade, e da construção das identidades dos indivíduos. Um sentido existencial que no «projeto imaginado da modernidade» (Wagner, 1996) se encontra no calor da esfera íntima, tantas vezes contraposto a uma esfera pública marcada pela frieza e pela impessoalidade das relações sociais.

Acoplada à felicidade e ao bem-estar do individuo está invariavelmente o prazer sexual. Este apesar de constantemente reivindicado nos falares juvenis, sob a égide de um individualismo liberto de constrangimentos e capaz de produzir, por esse exercício de liberdade, roteiros sexuais pessoais, foi muitas vezes afastado ou reprimido pelos educadores. No entanto, algo mudou.

Ao longo das incursões etnográficas, que levou à observação de mais de uma vintena de sessões de educação sexual nas escolas (23 no total), notámos que as intervenções educativas em contexto de sala de aula, pautam-se por um certo deslizamento de uma visão biomédica, para uma outra que compõe estes saberes com outros saberes de cunho psicossocial. Esta visão compósita, digamos biopsicossocial, prolonga um alinhamento entre a preocupação com a saúde e as preocupações com o bem-estar individual e social.

A introdução de temas que resultam da referida composição de elementos da vida sexual tem uma dupla finalidade: por um lado, a oxigenação e a animação destas sessões que se apresentam sempre (re) ajustadas às expectativas dos alunos, introduzindo tópicos que durante muito tempo foram evitados ou 
excluídos, apesar de fazerem naturalmente parte do presente vivido pelos jovens escolares. Por outro lado, o conhecimento é desta forma mais facilmente transformado num saber específico e comunicável, apto a circular entre os jovens. Tal como refere uma professora de uma escola do centro de Lisboa,

«Se soubermos aproximar-nos das suas vivências quotidianas, das suas dúvidas mais proeminentes, então os jovens ficam mais atentos para o que lhes queremos transmitir, nomeadamente para assuntos que os capacitem para viverem uma sexualidade segura e gratificante [...]》 (Excerto de entrevista a Professora de Biologia, 59 anos, 21 de outubro de 2015, Escola A).

Para a maioria dos professores, a dita visão biopsicossocial é já há muito tempo aquela que prevalece nas suas intervenções no âmbito da educação sexual. Porém, não existe uma visão acordada acerca deste procedimento. Essencialmente reivindicado pelos pais (como atrás se aludiu), mas também por alguns professores, a «instrução sexual», assente em elementos puramente advindos das ciências médicas, deve ser, segundo estes, a única a tomar presença nas sessões destinadas à educação sexual em meio escolar. Justificam a sua posição pelo receio de que uma intervenção educativa que combine elementos relacionados, por exemplo, com o prazer sexual, sejam capazes de instaurar entre os jovens um clima de experimentalismo e promiscuidade sem retorno.

Aliás, a qualificação dos adolescentes e jovens feita através da educação sexual escolar, em torno da consciencialização para a redução dos comportamentos de risco, centra-se em medidas suportadas no conhecimento médico e científico - o corpo físico- e toma a maioria do tempo despendido nas sessões dedicadas à educação sexual na escola.

Segundo esta perspetiva, e tendo em vista a promoção da saúde sexual, os alunos devem apropriar comportamentos saudáveis, corrigindo ou reorientando aqueles outros que, ao invés, sejam considerados nocivos para a sua saúde ou para a saúde pública. Esta lógica de prevenção, informa sobre os riscos a que os adolescentes e jovens estão acometidos caso não assumam uma postura de responsabilidade nas suas escolhas, ao mesmo tempo que incita aos controlos de saúde, às despistagens de infeções sexualmente transmissíveis e ao cuidado de si. A lógica subjacente a uma atitude responsável face aos riscos de índole sexual, assenta pois no princípio de que o(a) jovem deve agir a montante dos problemas de saúde, mais do que atender às pulsões do corpo de forma descuidada.

Esta lógica de prevenção, apesar de reunir a aprovação da maioria dos professores e dos pais, não deixa de ser criticada por outros seus congéneres. Segundo estes, uma educação sexual exclusivamente dedicada à prevenção de riscos, pode ser inadequada ou até opressiva, criando mais facilmente jovens programados do que jovens autónomos, já que algumas das preocupações profundamente pessoais, íntimas ou emocionais dos mesmos não são consideradas objetos de intervenção educativa se não assumirem formas reconhecíveis de uma gramática assente na promoção de um «estilo de vida saudável». Ademais, a mobilização desta gramática, é altamente adversa quando o jovem «imaturo» não dá provas de uma autonomia responsável suficientemente válida do ponto de vista da justificação pública (Dionísio, 2015).

Outras modalidades de educar a sexualidade juvenil nas escolas surgem no sentido de conjugar a gramática do «estilo de vida saudável» com uma outra referente à «formação de competências afetivas e relacionais»-o bem-estar do corpo biopsicossocial. Esta modalidade, que compõe entradas de uma lógica preventiva com outras lógicas afetivas e relacionais, ganha cada vez mais adeptos entre os professores e os pais e encarregados de educação. 
Em boa verdade, há um acordo construído em torno deste propósito. Este acordo dá-se em função de um argumentário preciso: a educação sexual é uma via importante para ajudar a resolver problemas de saúde pública e, por isso, deve contribuir para «prevenir» os «comportamentos de risco»; ao mesmo tempo que possui um cunho «socializadon», promovendo uma sexualidade «mais saudável», «mais consciente» e «mais informada», capaz ainda de consciencializar os jovens para o combate às desigualdades e injustiças sociais, culturais ou políticas, ligadas à vivência da sexualidade na sociedade contemporânea.

Neste sentido, apesar de não existir um acordo explícito e fechado entre aqueles que possuem uma visão favorável da educação sexual escolar e aqueles que se mostram mais apreensivos quanto à mesma, os «domínios do indesejável» são semelhantes, permitindo por isso chegar a um entendimento em torno de um propósito comum, ou dito de outra forma, de um lugar-comum: a construção de uma sexualidade mais saudável e mais consciente.

Este tipo de acordo fundado sobre lugares-comuns não permite a remoção total da conflitualidade, pois os motivos que levam os atores a construir certas afinidades surgem de intuitos diferentes, alguns deles diametralmente opostos. No entanto, leva à construção de um tipo de grandeza plural que assenta numa gramática a que Laurent Thévenot apelida de «gramática de afinidades pessoais a lugares-comuns» (Thévenot, 2014), caracterizada pela capacidade de integrar vozes dissonantes -sem a exigência de um desprendimento aos apegos pessoais- como forma de alcançar concepções diferentes do bem-comum (Thévenot, 2006), ou dito de outra forma, permitindo fazer o comum no plural (Resende, 2010).

Tratando-se de uma gramática desprovida de destacamento público, «várias expressões pessoais encontram um terreno comum para comunicar profundas preocupações, apegos e sentimentos» (Thévenot, 2014: 32). O referido argumentário possibilita o acordo entre vozes dissonantes, nomeadamente entre a família e a escola, em relação à educação sexual, como uma lógica capaz de integrá-los de maneira inteligível, estabelecendo traços pertinentes e reconhecíveis pelos diversos atores.

Importa ainda sublinhar que este acordo, assente em posições divergentes, ou por vezes, conflituantes, está sempre em risco de ser desfeito. Com efeito, dada a plasticidade dos lugares-comuns, e destes não serem precisamente definidos como objetos qualificados para um bem-comum (Thévenot, 2014), são sempre passiveis de serem usados para fazer, desfazer e refazer acordos.

Resta acrescentar que os lugares-comuns possuem uma grande variação inter-escalar, que vai do íntimo ao altamente globalizado, dando sentido simultâneo ao público e ao privado. Por exemplo, uma família constituída por pais e filhos conta com o apoio de lugares-comuns específicos, lugares emocionalmente investidos que pertencem exclusivamente à intimidade familiar. Porém, estes lugares-comuns, de alcance muito limitado, podem encontrar um maior número de afinidades pessoais, ficando progressivamente maiores. Aliás, podemos observar que a maioria das mobilizações em relação à educação sexual escolar são geradas a partir de problemas que afetam o ambiente próximo e familiar do quotidiano. Das conversas informais havidas entre encarregados de educação, até às Associações de Pais, seguindo para os Conselhos Pedagógicos e para as Direções das instituições educativas, o que começa no domínio privado vai percorrendo uma escala cada vez mais ampla, fazendo a sua aparação mais tarde ou mais cedo no domínio público.

\section{Notas Finais}

Integrar vozes em vários tons sobre a batuta das afinidades a lugares-comuns 
Ao longo deste artigo exploramos empiricamente as dificuldades que existem em ajustar e gerir as expectativas entre pais e profissionais de ensino, ou de uma forma mais geral, entre a escola e a família, em relação à educação sexual escolar; cada uma (re)enviando injunções para a outra por forma a garantir a boa educação dos adolescentes e jovens sobre esta matéria.

Apesar da maioria dos pais aceitar que os seus filhos sejam educados pela escola no que diz respeito à sexualidade, esta não deixa de gerar inquietações várias entre os mesmos. Receiam essencialmente que outros padrões morais desordenem os valores transmitidos pela família. Ou seja, que a sua capacidade de escrutínio vigilante sobre a educação sexual escolar não seja suficiente para garantir que a sua própria visão sobre a sexualidade. E que esta, frequentemente centrada no afeto e no amor, transmitida aos filhos numa sucessão temporal planeada segundo a percepção da sua maturidade, não se harmonize com a escala de valores transmitidos pela escola e com as temporalidades definidas pela mesma.

Contudo, o estudo empírico realizado nas escolas, mostra um cenário mais versátil e complexo. Por exemplo, as entrevistas realizadas aos educadores, mostram que o conjunto de valores morais aí transmitidos, em tempos de educação sexual, se aproxima dos valores que são defendidos pela maioria dos pais entrevistados: «[...] afinal também somos pais e mães» (Professora do 3. ${ }^{\circ}$ ciclo, 43 anos, escola C), como afirma uma professora entrevistada.

A pesquisa sobre a educação sexual nas escolas mostra que apesar das controvérsias advindas das contendas entre atores da escola e da família, o acordo que permite a sua legitimação em meio escolar, depende não só de uma complexa e sofisticada combinação de ordens de grandeza (cívica e doméstica) (Boltanski, Thévenot, 1991), mas também, e fundamentalmente, pela afinidade que estes atores encontram a lugares-comuns, por exemplo na fabricação de uma autonomia assente num «estilo de vida saudável».

O clima de pluralismo moral do quotidiano, que alimenta a dúvida inquietante dos pais, é de certa forma reduzido na escola -em casos pontuais, trazem até resquícios tradicionalistas- levantando outros dilemas, quando esses ensinamentos se distanciam em medida de verosimilhança das vidas reais vividas num mundo em constante transformação.

A este respeito, recriam-se no quotidiano novos sentidos para a liberdade sexual, que são constantemente questionados e permanentemente (re)construídos. Por vezes, nem as famílias, nem a escola parecem capacitadas para acompanhar o ritmo frenético das injunções trazidas pelo advento das novas tecnologias de informação e comunicação e das mutações técnicas sociais e culturais que se impõem como um dos traços mais característicos das sociedades da modernidade avançada.

A proliferação dos dispositivos digitais de informação e comunicação, enquanto dispositivos de sedução para a novidade e para o experimentalismo, exploram fortemente a embriaguez das sensações e das emoções novas, a intensificação do prazer, a libertação da sexualidade, ao mesmo tempo que lançam promessas de suspensão das rotinas, o alívio do peso de várias frustrações e insatisfações que o jovem enfrenta no seu quotidiano (Auray, 2002). São lugares-comuns construídos em torno da paixão do indivíduo moderno pela novidade, aquilo que Alexis de Toqueville designa pela necessidade da procura incessante pelo «inesperado e o novo, emoções vivas e rápidas [...] que lhes permita sair imediatamente de si próprios» (Toqueville, 1961: 197), da rotina, do aborrecimento.

Proteger os adolescentes e os jovens das «armadilhas» de uma era digital que incita à felicidade consumista, à libertação dos prazeres do corpo e dos sentidos, lançar os jovens em aventuras sexuais despreo- 
cupadas, na adrenalina do experimentalismo é, a par da construção de uma vida sexual saudável, outro tópico social a merecer uma intervenção educativa organizada.

De certo, a lógica de proteção juvenil, presente nos programas de educação sexual da atualidade, são reconhecidamente «ações que convêm» (Thévenot, 1990) aos vários atores envolvidos e à legitimação dos processos, particularmente importante para pensar sentidos de coordenação entre a escola e a família que são historicamente afinidades difíceis, mas possíveis, de afinar.

\section{Referências bibliográficas}

Aboim, Sofia (2013). A Sexualidade dos Portugueses. Lisboa: Relógio de Água Editores, Lda.

Auray, Nicola (2002): "Sociabilité informatique et différence sexuelle" en Danielle Chabaud-Rychter; Delphine Gardey (Eds.): L'engendrement des choses. Des hommes, des femmes et des techniques. Paris: Éditions des archives contemporaines.

Boltanski, Luc y Thévenot, Laurent (1991). De la Justification. Les Économies de la Grandeur. Paris: Gallimard.

Breviglieri, Marc (2005): "Bienfaits et méfaits de la proximité dans le travail sociale" en Jacques Ion (Ed.): Le travail sociale en débat(s). Paris: Éditions La Découverte.

Breviglieri, Marc (2007): “L'arc expérientiel de l'adolescence: esquive, combine, embrouille, carapace et étincelle...". Education et sociétés,19, 99-113.

Breviglieri, M. (2009): “L'insupportable: l'excès de proximité, l'atteint à l'autonomie et le sentiment de violation du privé" en Danny Trom, Claudette Lafaye \& Marc Breviglieri (Dir.): Compétences critiques et sens de la justice. Paris: Economica.

Diário da República (2010): "Decreto-Lei no 60 de 9 de Agosto de 2009”. Diário da República, 1. a série -N. 69 - 9 de abril de 2010.

Dionísio, Bruno (2015): “O que os orientadores fazem com os alunos? O trabalho de preparação das competências para uma carreira de escolhas" en Maria Manuel Vieira (Org.): O futuro em aberto. Lisboa: Editora Mundos Sociais.

Dubet, François (2002). Le Déclin de l'Institution. Paris: Seuil.

Elias, Norbert (1991). La société des individus. Paris: Fayard.

Gore, Fiona; Bloem, Paul; Patton George; Ferguson Jane; Joseph Véronique; Coffey, Carolyn; Sawyer Susan; Mathers, Colin (2011): "Global burden of disease in young people aged 10-24 years: a systematic analysis”. Lancet. Published online June 7, 2011 DOI:10.1016/S0140- 6736(11)60512-6

Ichheiser, Gustav (1949). Misunderstandings in human relations : a study in false social perception. Chicago: University of Chicago Press.

Lazarus; Jeffrey, Sihvonen-Riemenschneider; Henna, Laukamm-Josten, Ulrich; Wong Fiona; Liljestrand, Jerker (2010). "Systematic review of interventions to prevent the spread of sexually transmitted infections, including HIV, among young people in Europe”. Croatian Medical Journal, 51 (1), 74-84.

Mota, Fábio (2017): “Entre o decente e o justo: racismo e cisma na cidade do Rio de Janeiro” en José Manuel Resende e Alexandre Martins (Org): (Con)vivemos numa sociedade justa e decente? críticas, envolvimentos e transformacões. Porto: Fronteira do Caos Editora (No prelo). 
Pasquier, Dominique (2005). Cultures lycéennes: la tyrannie de la majorité. Paris: Éd. Autrement.

Pattaroni, Luca (2002): “Les compétences de l'individu: travail social et responsabilisation” en Vivianne Chatel y Marc-Henry Soulet (Dir.): Faire face et s'en sortir. Fribourg: Editions Universitaires, vol. 2.

Pattaroni, Luca (2007): “Le sujet en l'invidu. La promesse d'autonomie du travail social au risque d'une colonisation par le proche" en Favrizio Cantelli y Jean-Louis Genard (Ed.): Action publique et subjectivité. Paris: LGDJ.

Reis, Margarida; Vilar Duarte (2004): “A implementação da educação sexual na escola: Atitudes dos professores”. Análise Psicológica, 22 (4), 737-745.

Resende, José Manuel (2010). A Sociedade contra a Escola? A Socialização Política num contexto escolar de incerteza. Lisboa: Edições Piaget.

Resende, José Manuel; Beirante, David; Gouveia, Luís (2016): “É possível usar a pedagogia na educação sexual? A qualificação política professoral das sexualidades e dos afetos em questão" en Mariana Gaio Alves, Leonor Lima Torres e Pedro Abrantes (Orgs.): A educaşão na Europa do Sul. Constrangimentos e desafios em tempos incertos. $1^{\text {a }}$ Conferência Ibérica de Sociologia da Educação. Lisboa: Universidade Nova de Lisboa. Em repositório: http:/ /www.aps.pt/index.php?area=302

Shepherd Jonathan; Kavanagh Josephine; Picot Joanna; Cooper Keith; Harden Angela; Barnett-Page Elaine; Jones, Jeremy et al., (2010): “The effectiveness and costeffectiveness of behavioural interventions for the prevention of sexually transmitted infections in young people aged 13-19: a systematic review and economic evaluation”. Health Technology Assessment, 14 (7).

Taylor, Charles (2005). Le Malaise de la Modernité. Paris: Les Éditions du CERF.

Thévenot, Laurent (1990): “L'action qui convient” en Patrick Pharo et Louis Quéré (Dir.). Les formes de l'action. Paris: Ed. de l'EHESS.

Thévenot, Laurent (2006). L'action au pluriel. Sociologie des regimes d'engagement. Paris: Éditions La Découverte.

Thévenot, Laurent (2014): "Voicing, concern and difference. From public spaces to common-places". European Journal of Cultural and Political Sociology, 1, 7-34.

Toqueville, Alexis de (1961). De la démocratie en Amérique, t. 1, vol. II. Paris: Gallimard.

Wagner, Peter (1996). Liberté et Discipline. Les Deux Crises de la Modernité. Paris: Métailié.

\section{Notas biográficas}

José Manuel Resende es sociólogo, Membro integrado do CICS. NOVA (Centro Interdisciplinar de Ciências Sociais da Universidade Nova de Lisboa - Portugal) colaborador do Programa de Pós-Graduação da UENF-Brasil, colaborado do OPJ do ICS, e consultor externo do INCT-InEAC da UFF-Brasil e do LeMetro da UFRJ-Brasil.

David Beirante es Doutorando em Sociologia, Membro do CICS. NOVA (Centro Interdisciplinar de Ciências Sociais da Universidade Nova de Lisboa - Portugal).

Luís Gouveia es Sociólogo, Membro Integrado do CICS. NOVA (Centro Interdisciplinar de Ciências Sociais da Universidade Nova de Lisboa - Portugal). 